Bio - grafia. Escritos sobre la Biología y su Enseñanza. ISSN 2027

Edición Extraordinaria. p.p. 412 - 423

Memorias del VIII Encuentro Nacional de Experiencias en Enseñanza de la Biología y la Educación Ambiental. III Congreso Nacional de Investigación en Enseñanza de la Biología.

\title{
EIXOS TEÓRICOS SOBRE A ESTRATÉGIA ARGUMENTATIIVA NO ENSINO DE BIOLOGIA
}

\author{
THEORETICAL AXIS ON THE ARGUMENTATIVE STRATEGY IN BIOLOGY \\ TEACHING
}

\section{Severo, Thiago Emmanuel Araújo ${ }^{1}$}

\section{Resumo}

B

I

0

$P$

0

$N$

E

$N$

c

I

A

${ }^{1}$ Universidade Federal do Rio Grande do Norte (UFRN) - Brasil. Departamento de Práticas Educacionais
e Currículo - DPEC. E-mail: thiagosev@gmail.com 412 
Bio - grafia. Escritos sobre la Biología y su Enseñanza. ISSN 2027

Edición Extraordinaria. p.p. 412 - 423

Memorias del VIII Encuentro Nacional de Experiencias en Enseñanza de la Biología y la Educación Ambiental. III Congreso Nacional de Investigación en Enseñanza de la Biología.

\begin{abstract}
The critical thinking is a strong characteristic of the scientific knowledge. The science education that assume a more narrow relationship with the scientific culture, not just its knowledge, should promote a reflection on the development and effects of these models of thought. Investing in the argumentative dialogue in the classroom can be an exercise to build this model of critical and analytical thinking, taking into account the diverse sources of information and explanatory models involved in the craft of science. In order to promote this science education, its necessary to a prioritize dialogic practice, which promotes in students a willingness to hear different ideas, read and analyze data and filter what serves better in the making of explanations about any phenomenon. Given the current trends in science education, the objective of this article is to map some theoretical basis that problematize the use of scientific characteristics in the classroom, such as investigative reporting of results through the argument.
\end{abstract}

Key-words: argumentation, inquiry, Science education.

Introdução

Um dos principais objetivos do ensino de ciências é facilitar a aproximação dos estudantes ao conhecimento já construído e consolidado pela cultura científica (MEC/BRASIL, 2006; A. Villani \& Pacca, 1997). Mas não apenas isso, uma vez que o ensino de ciências prioriza, também, encorajar os alunos a desenvolver uma ação social mais responsável a partir de questões pertinentes a sua realidade (Ratcliffe, 1998). Para isso é necessário saber ler, interpretar e organizar as informações disponíveis, o que demanda capacidade de argumentação e destreza narrativa (Santos, Mortimer, \& Scott, 2001).

Tendo em vista as tendências atuais para o ensino de ciências, o objetivo deste artigo é mapear bases teóricas que problematizem o uso das características do fazer cientifico em sala de aula, como a comunicação dos resultados investigativos por meio da argumentação. Esse ensaio tem como finalidade ampliar o campo de diálogo, limitações e possibilidades da utilização de práticas mais próximas da cultura cientifica em espaços reais de ensino. 
Bio - grafia. Escritos sobre la Biología y su Enseñanza. ISSN 2027

Edición Extraordinaria. p.p. 412 - 423

Memorias del VIII Encuentro Nacional de Experiencias en Enseñanza de la Biología y la Educación Ambiental. III Congreso Nacional de Investigación en Enseñanza de la Biología.

Talvez a construção das sessões seguintes tenha gravitado ao redor da seguinte ideia: a argumentação é um processo importante não só para a ciência, mas para a organização do conhecimento em geral. Por consequência, a prática da argumentação pode ser promovida nos cursos de formação do Biólogo e no ensino médio a partir de modelos didáticos que privilegiem o pensamento crítico reflexivo.

\section{A crítica e a construção do conhecimento cientifico em três cenários}

A atividade crítica é também o esperado de todos quantos se dedicam à ciência. Analisar de forma crítica as construções teóricas da ciência significa assumir uma atitude política (Almeida, 2010; Morin, 2004). Isso quer dizer que o ensino de ciências deve promover uma reflexão sobre a emergência, o desenvolvimento e os efeitos dos modelos de pensamento. $A$ fim de desdobrar esta reflexão, o presente projeto tem como ponto de partida sumariar três cenários distintos da ciência, que expõem três momentos de bifurcação do conhecimento na área da biologia.

Em um primeiro cenário, no dia 25 de abril de 1953, a revista Nature publicou o artigo Molecular Structure of Nucleic Acids (Estrutura Molecular dos Ácidos Nucleicos). Neste trabalho Francis Crick e James Watson concluíram que a estrutura do DNA é semelhante a uma dupla hélice, ou seja, apresenta duas cadeias em espiral unidas por pares de bases complementares. $O$ trabalho destes dois bioquímicos foi um marco para a ciência moderna e para a forma como compreendemos o DNA.

Amplamente aceito, o argumento proposto por Watson e Crick para justificar o modelo da dupla hélice foi organizado a partir de uma convergência de resultados de pesquisas e de proposições teóricas de diversas ordens: a pesquisa de Linus Pauling sobre a anemia falciforme, sugerindo que a forma de certas proteínas apresenta uma hélice alfa; os resultados encontrados por Erwin Chargaff, indicando quantidades iguais de nucleotídeos no DNA; a construção empírica de Alfred Hershey e Martha Chase, confirmando que o DNA é a molécula que medeia a hereditariedade; e as pesquisas de Maurice Wilkins e Rosalind Franklin, que por meio das imagens de raios $X$ de cristais de DNA demonstraram que a molécula apresenta uma estrutura helicoidal. 
Bio - grafia. Escritos sobre la Biología y su Enseñanza. ISSN 2027

Edición Extraordinaria. p.p. 412 - 423

Memorias del VIII Encuentro Nacional de Experiencias en Enseñanza de la Biología y la Educación Ambiental. III Congreso Nacional de Investigación en Enseñanza de la Biología.

Segundo cenário. O biólogo naturalista Charles Darwin utilizou a teoria da população de Malthus, ou uniformitarismo de Lyell, juntamente com os dados empíricos que reuniu em sua viagem a bordo do Beagle pela América Central e América do Sul para tecer a sua ousada proposição da Seleção Natural. No caso de Darwin, além de justificar o seu argumento, foi necessário convencer o público, tanto acadêmico quanto da comunidade em geral, que os animais e as plantas tinham mudado, e que as espécies que vivem na Terra descendem de outras espécies, em vez de ter de ser criados todos de uma vez, como era o que se comumente acreditava até então (Erduran \& Jiménez-Aleixandre, 2007).

Darwin estava ciente de que a tarefa de persuadir seus contemporâneos não seria fácil. Essa foi uma das razões pelas quais ele atrasou a publicação de seu livro em longos vinte anos. De fato, uma apresentação conjunta por Darwin e Wallace no Linnean Society em 1858 despertou pouquíssimo interesse, e o presidente da sociedade concluiu que aquele ano, efetivamente, não teria sido marcado por nenhuma descobertas memoráveis que fazem revolucionar a ciência (Beddall, 1968). No entanto, um ano depois, a publicação do livro de Darwin iniciou uma grande controvérsia entre pontos de vista díspares e vertentes teóricas distintas (Erduran \& Jiménez-Aleixandre, 2007, p. 3).

Por fim, em um terceiro cenário. Esse, expresso nos domínios dos saberes da tradição, portanto ao lado da cultura científica, deve ser compreendido como complementar aos estudos consagrados da ciência acadêmica. Chico Lucas, morador da comunidade Areia Branca, Lagoa do Piató, localizada na região semiárida do Rio Grande do Norte, tem vivido e ensinado uma 'ecologia das ideias e da ação', uma maneira transdicsiplinar de ler a Natureza. A partir dos ensinamentos de seu pai, o talento de Chico Lucas foi sendo tecido frente às necessidades e dificuldades do ecossistema da região. Talentos como a pesca, caça, agricultura, construção de canoas e predição do tempo, constituem juntos domínios diversos dos saberes plurais construídos com o passar do tempo, como o próprio Chico Lucas confessa na obra A Natureza me disse (Silva, 2008). 
Bio - grafia. Escritos sobre la Biología y su Enseñanza. ISSN 2027

Edición Extraordinaria. p.p. 412 - 423

Memorias del VIII Encuentro Nacional de Experiencias en Enseñanza de la Biología y la Educación Ambiental. III Congreso Nacional de Investigación en Enseñanza de la Biología.

Pescador experiente, Chico Lucas construiu uma verdadeira ecologia dos saberes técnicos "onde realça o papel de diferentes fatores que se entrecruzam nesse processo: socioeconômicos, ambientais, entre outros" (Tabosa, 2007, p. 152). Frente a um problema de escassez dos recursos de pesca, Chico Lucas desenvolveu um verdadeiro relatório de impacto ambiental a partir de sua leitura detalhada e sistemática da região, onde ele relaciona o desmatamento da aba da serra, de onde veem as nascentes da lagoa, à eutrofização do corpo d'água e ao consequente desequilíbrio na cadeia trófica. Em visitas à lagoa do Piató durante o ano de 2012, Chico Lucas me levou pessoalmente ao campo onde conduz as suas observações - da aba da serra às margens da lagoa - fazendo questão de demonstrar empiricamente como construiu os dados que davam suporte à sua leitura do impacto ambiental que está ocorrendo na lagoa.

Em certa ocasião, Chico Lucas me contou que as redes de pesca de malhas mais finas sujavam com facilidade com o lodo presente na lagoa, e para retirar esse lodo ele as colocava em um tanque cheio de água com cal - o resultado era sempre uma rede limpa. A repetição desta experiência prática foi um operador cognitivo para que ele relacionasse 0 que estava causando a redução do lodo na lagoa. Mas apenas constatar não era suficiente, 0 argumento de Chico Lucas convergiu para o impacto nas nascentes da lagoa localizadas na aba da serra, onde é realizada com frequência a extração de material vegetal e a liberação do material calcário, como diz o próprio Chico em entrevista à Wyllys Tabosa (2009, p. 146).

Sobre a exploração dos recursos vegetais, Chico Lucas descreve:

Os cortadores de lenha junto com o proprietário tiraram a lenha. Isso é um trabalho que não era para eles fazerem, até porque todo mundo é consciente da agressão que o homem faz ao ambiente, e isso está acima de uma agressão ao meio ambiente. Você vê aqui que está totalmente desertificado: a mata foi tirada até o calcário.

Relacionado a esta prática de depredação dos recursos, há uma compreensão das consequências em larga escala. Sobre o assoreamento, explica: 
Bio - grafia. Escritos sobre la Biología y su Enseñanza. ISSN 2027

Edición Extraordinaria. p.p. 412 - 423

Memorias del VIII Encuentro Nacional de Experiencias en Enseñanza de la Biología y la Educación Ambiental. III Congreso Nacional de Investigación en Enseñanza de la Biología.

O riacho trabalhando só em cima do calcário, e isso é uma coisa totalmente prejudicial aos lagos. $O$ homem é que está contribuindo para jogar o próprio calcário nas nascentes. Em todo esse subsolo, quando dá uma chuva, a massa, a goma do calcário, vai daqui $100 \%$ para dentro do lago. $O$ calcário, ele tem um material que elimina 0 lodo, os planctos da água e aí não vai ter alimento para o peixe.

A leitura sofisticada da Natureza construída por Chico Lucas faz relação com os desequilíbrios ambientais causados pela variação das dinâmicas tróficas da lagoa, mas, de forma ampliada, também com os efeitos desta relação. Sobre estes eventos, ele amplia:

A maior parte do povo não conhece isso, acha que cortando essa lenha ele vai comprar um peixe melhor lá na beira da lagoa. Ele vai dizer: -rapaz esse peixe está magro, por quê? Ele mesmo contribuiu para que aquele peixe estivesse magro, não tem a menor ideia do que ele fez com a natureza.

Apesar dos três cenários descritos se situarem em espaços distintos dentro da academia e fora dela existe uma estrutura comum que os parasita e é universal a qualquer sistematização de informações contextualizada: a argumentação. $O$ desenvolvimento da argumentação em todos os casos foi necessário para explicitar a natureza e aceitabilidade das informações que dão suporte ao pensamento construído (Santos et al., 2001). A partir destes exemplos, podemos perceber que o ato de argumentar emerge a partir de dois aspectos fundamentais, como propõe Sibel Erduran e María Jímenez-Aleixandre (2007). 0 primeiro aspecto relaciona-se com a justificativa de asserções de conhecimento, que agrupa linhas convergentes de raciocínio, ideias teóricas e evidências empíricas para uma afirmação. $O$ segundo aspecto tem a ver com a argumentação como persuasão, ou seja, explicar a relevância de uma organização de pensamento para um determinado contexto ou público.

\section{Construindo modelos de compreensão do mundo}


Bio - grafia. Escritos sobre la Biología y su Enseñanza. ISSN 2027

Edición Extraordinaria. p.p. 412 - 423

Memorias del VIII Encuentro Nacional de Experiencias en Enseñanza de la Biología y la Educación Ambiental. III Congreso Nacional de Investigación en Enseñanza de la Biología.

Os argumentos de Darwin, Watson, Crick e Chico Lucas passaram a ser modelos teóricos aceitos e pertinentes para um determinado contexto porque foram sistematizados de forma convergente a partir de uma racionalidade aberta, com suporte tanto em construções teóricas quanto em constatações empíricas. Para isso, é necessário saber ler e avaliar bem a multiplicidade de informações que compõem a Natureza e construir padrões de organização que suportem a maior quantidade de ruído, a fim de melhor compreender sua dinâmica em uma perspectiva dialógica (Morin, 2007).

Notadamente, espaços que incentivem a construção do conhecimento a partir da argumentação científica precisam ser privilegiados não só nos cursos de formação de professores, mas também como prática social, uma vez que, de acordo com Santos, Mortimer e Scott (2001),

ajudar o aluno a melhorar a sua argumentação possibilita desenvolver - espírito de análise na escolha com mais confiança entre as diferentes alternativas, a partir das várias fontes de informações e dos vários modelos explicativos para o processo envolvido (p.2).

$O$ incentivo para que os alunos fundamentem os seus argumentos, sabendo escolher bem 0 modo de expor seu conflito e explicitando a natureza das informações por eles usadas é um importante fator para auxiliá-los a desenvolver a capacidade de tomada de decisão (Ratcliffe, 1998). Para isso, torna-se necessária a estruturação de modelos e novas práticas (Erduran \& Jiménez-Aleixandre, 2007) pedagógicas que contemplem a construção e realização do diálogo crítico, uma vez que há uma explícita influência do contexto pedagógico de sala de aula sobre a qualidade dos argumentos dos alunos (Geddis, 1991). Certamente, a capacidade de argumentar enquanto estratégia durante o ensino de ciências direciona os alunos para questionamentos fulcrais para a compreensão do que seja 0 processo de construção do conhecimento. Por exemplo: Como as ideias são produzidas, avaliadas e revisadas na ciência? Ou, de forma mais incisiva, como explicar o que sabemos?

Espaços de troca e construção de conhecimento 
Bio - grafia. Escritos sobre la Biología y su Enseñanza. ISSN 2027

Edición Extraordinaria. p.p. 412 - 423

Memorias del VIII Encuentro Nacional de Experiencias en Enseñanza de la Biología y la Educación Ambiental. III Congreso Nacional de Investigación en Enseñanza de la Biología.

Nos últimos anos diversas pesquisas (Erduran \& Jiménez-Aleixandre, 2007; Fujii, 2011; Kuhn, 1993; Layrargues, 2002; Luca \& Kubo, 2011; Santos et al., 2001; C. E. P. Villani \& Nascimento, 2003) sobre o ensino de ciências tem discutido a argumentação como ferramenta pedagógica que dê um suporte maior a superficialidade dos programas curriculares, dos materiais didáticos e das estratégias tradicionais de transmissão de conteúdo. O trabalho com a argumentação, nesta perspectiva, é um grande aliado para incluir no ensino disciplinar valores como a cidadania, a formação ética dos indivíduos e o pensamento crítico.

A partir de um estudo de caso com professores do ensino médio, Santos, Mortimer e Scott (2001) constataram que existem dificuldades na utilização da argumentação em sala de aula. Por parte dos alunos, essas dificuldades se encontram na não familiaridade deles com este tipo de linguagem, ou com a não necessidade de justificar o conhecimento construído. Por parte dos professores, existem dificuldades relativas ao planejamento, condução do debate e suporte conceitual dos alunos. Os autores apresentam que "tradicionalmente, 0 ensino de ciências tem dado pouca atenção para a argumentação e que poucos professores dão oportunidade para os seus alunos argumentarem em sala de aula" (Santos et al., 2001, p. 11).

Investir em um diálogo argumentativo em sala de aula é uma forma de desenvolver um "espírito de análise na escolha com mais confiança entre as diferentes alternativas, a partir das várias fontes de informações e dos vários modelos explicativos para o processo envolvido" (Santos et al., 2001, p. 2).

Fomentar um ensino de ciências que prepare o indivíduo para esta 'cultura da complexidade' significa ultrapassar as 'monoculturas da mente'. Para isso, torna-se necessário ter disponibilidade de espírito para ouvir o outro, as ideias distintas, e filtrar o que the serve ali, o que há de bom. A arte de argumentar bem torna possível esta troca, uma vez que incita o compartilhamento e a mediação das opiniões. Este é, segundo, Gonçalves-Maia, "um exercício de pensamento original sobre conhecimentos anteriores". Daí porque dialogar, trazer a tona, discutir e até mesmo refutar os conhecimentos já construídos "revela ambições de conhecer, ou melhor, de saber" (2011 p, 20). 
Bio - grafia. Escritos sobre la Biología y su Enseñanza. ISSN 2027

Edición Extraordinaria. p.p. 412 - 423

Memorias del VIII Encuentro Nacional de Experiencias en Enseñanza de la Biología y la Educación Ambiental. III Congreso Nacional de Investigación en Enseñanza de la Biología.

Erduran e Jímenez-Aleixandre (2007) concebem que a argumentação deve ser parte integrante no ensino de como uma solução para alguns problemas de aprendizagem, na medida em que ajuda os alunos a aprenderem conceitos e cenários mais difíceis que exigem análise e avaliação de dados e como uma ferramenta potencial para ajudar a melhor compreender e apoiar os processos de aprendizagem na sala de aula. As pesquisadoras apontam, ainda, que existem pelo menos cinco dimensões entrelaçadas ou "potenciais contribuições da introdução da argumentação nas aulas de ciências" (Erduran \& JiménezAleixandre, 2007, p. 5):

- Dar apoio aos processos cognitivos e metacognitivos que dão suporte ao pensamento através de modelos para os alunos.

- Desenvolver competências comunicativas e, particularmente, o pensamento crítico.

- Aproximar os estudantes dos conhecimentos científicos e capacitá-los a falar e escrever utilizando a linguagem científica.

- Apoiar a aproximação da cultura escolar nas práticas da cultura científica e o desenvolvimento de critérios epistêmicos para avaliação do conhecimento.

- Apoiar o desenvolvimento do raciocínio, especialmente a escolha de teorias ou posições com base em critérios racionais.

Estes pontos são partes complementares de uma mesma estratégia de ensino, como pode ser visualizado na Figura 1. A introdução destas perspectivas em sala de aula demanda uma iniciativa de organização tanto pedagógica quanto curricular (Erduran \& JiménezAleixandre, 2007).

Figura 1: Contribuições potenciais da Argumentação. Traduzido e ampliado (partes em azul) de Erduran e Jiménez-Aleixandre (2007). 
Bio - grafia. Escritos sobre la Biología y su Enseñanza. ISSN 2027

Edición Extraordinaria. p.p. 412 - 423

Memorias del VIII Encuentro Nacional de Experiencias en Enseñanza de la Biología y la Educación Ambiental. III Congreso Nacional de Investigación en Enseñanza de la Biología.

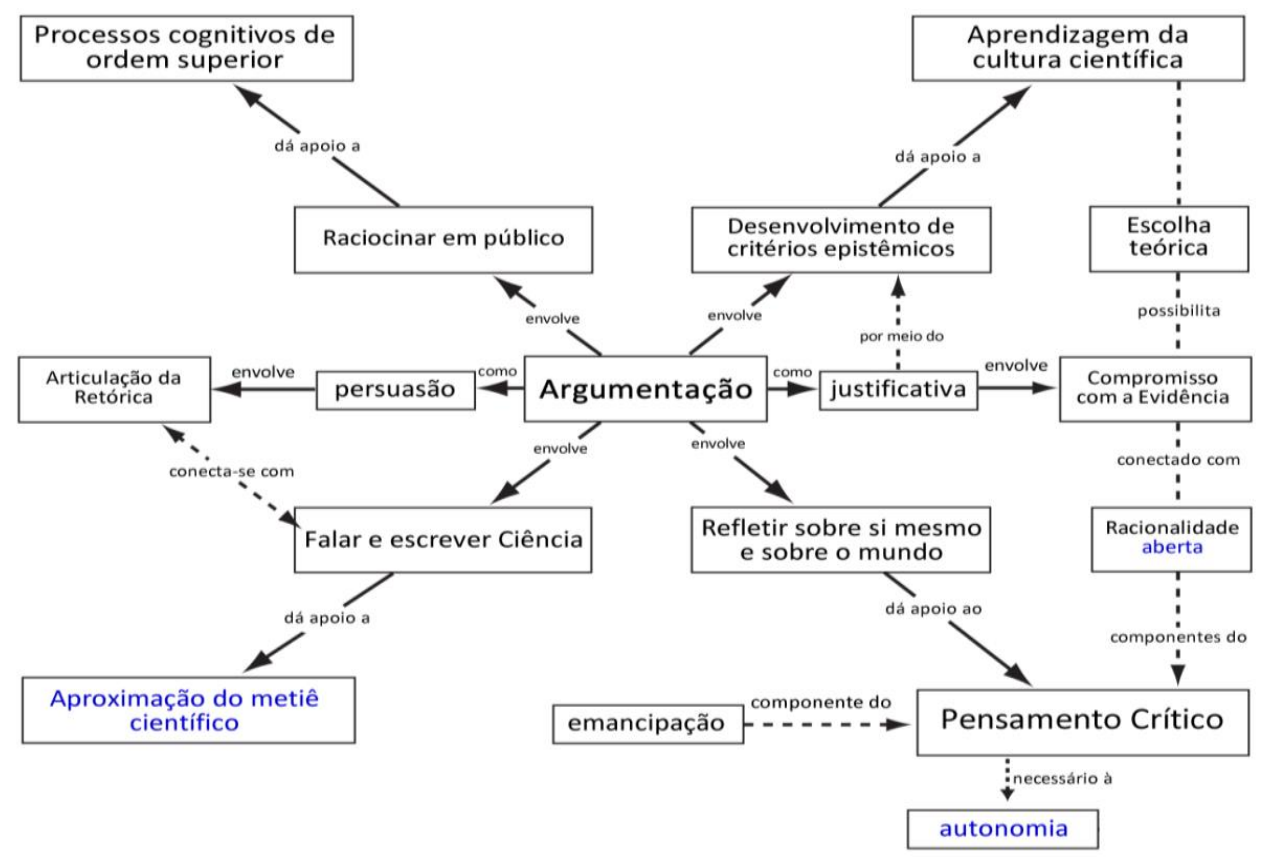

Por uma abertura do campo argumentativo

Como apontam Villani e Nascimento (2003), as novas orientações das pesquisas em educação têm mostrado "as importantes contribuição das investigações que privilegiam a análise da dimensão discursiva dos processos de ensino e aprendizagem de Ciências em situações reais de sala de aula. Esses estudos destacam o papel da linguagem como elemento fundamental para a aquisição do conhecimento científico escolar" (C. E. P. Villani \& Nascimento, 2003, p. 187).

Nesta perspectiva, ser capaz de trabalhar com dados, sejam eles construídos pelos alunos ou apresentados pelo professor, é necessário para um ensino de ciências mais investigativo, mas necessita incluir também a pratica argumentativa, para ter proximidade com um exercício explicativo.

Como forma de ampliar o pensamento na direção de uma nova organização da ciência (Bachelard, 1995), não limitada pelas fraturas disciplinares ou pelas explicações pontuais mecânicas, torna-se necessário facilitar o desenvolvimento de critérios epistêmicos inerentes ao pensar e ao fazer ciências na escola. Para isso é possível privilegiar, durante 
Bio - grafia. Escritos sobre la Biología y su Enseñanza. ISSN 2027

Edición Extraordinaria. p.p. 412 - 423

Memorias del VIII Encuentro Nacional de Experiencias en Enseñanza de la Biología y la Educación Ambiental. III Congreso Nacional de Investigación en Enseñanza de la Biología.

os cursos de formação em ciências, e durante o ensino médio, estratégias de método que contribuam para aumentar a capacidade argumentativa dos alunos (C. E. P. Villani \& Nascimento, 2003), tendendo sempre para um diálogo que aproxime contextos atuais com a produção do conhecimento cientifico de forma que tenha significado para a vida dos estudantes.

\section{REFERÊNCIAS}

Almeida, M. d. C. d. (2010). Complexidade, saberes científicos, saberes da tradição. São Paulo: Editora Livraria da Física.

Bachelard, G. (1995). O novo espírito científico. Rio de Janeiro: Tempo Brasileiro.

Beddall, B. G. (1968). Wallace, Darwin and natural selection: A study in the development of ideas and attitudes. Journal of the History of Biology, 1, p. 261-323.

Erduran, S., \& Jiménez-Aleixandre, M. P. (2007). Argumentation in Science Education: An Overview. In M. P. Jiménez-Aleixandre \& S. Erduran (Eds.), Argumentation in Science Education: Springer.

Fujii, R. S. (2011). O RPG Como Ferramenta de Ensino: as contribuições do RPG para a argumentação no ensino de Biologia. Contexto \& Educação(86), 102-118.

Geddis, A. N. (1991). Improving the quality of science classroom discourse on controversial issues. Science Education, 75(2), 169-183.

Gonçalves-Maia, R. (2011). Ciência, pós-ciência, metaciência: tradição, inovação e renovação (19adição ed.). São Paulo: Editora Livraria da Física.

Kuhn, D. (1993). Science as argument: implications for teaching and learning scientific thinking. Science Education, 77(3), 319-337.

Layrargues, P. P. (2002). Muito prazer, sou a educação ambiental, seu novo objeto de estudo sociológico. Paper presented at the I Encontro da Associação Nacional de Pós Graduação e Pesquisa em Ambiente e Sociedade, Indaiatuba.

Luca, G. G. d., \& Kubo, O. M. (2011). O argumentar como objetivo de ensino a ser desenvolvido em diferentes disciplinas e desde níveis básicos do ensino formal. Psicologia da Educação - São Paulo(33), 153-160.

MEC/BRASIL. (2006). Parâmetros Curriculares Nacionais, Ciências da Natureza, Matemática e suas Tecnologias. Brasília: MEC/SEF. 
Bio - grafia. Escritos sobre la Biología y su Enseñanza. ISSN 2027

Edición Extraordinaria. p.p. 412 - 423

Memorias del VIII Encuentro Nacional de Experiencias en Enseñanza de la Biología y la Educación Ambiental. III Congreso Nacional de Investigación en Enseñanza de la Biología.

Morin, E. (2004). A Cabeça bem Feita (10ª Edição ed.). Rio de Janeiro: Bertrand Brasil.

Morin, E. (2007). Os Sete Saberes Necessários à Educação do Futuro. Brasília: UNESCO.

Ratcliffe, M. (1998). Discussing socio-scientific issues in science lessons - pupils' actions and the teacher's role. School Science Review, 79(288), 55-59.

Santos, W. L. P. d., Mortimer, E. F., \& Scott, P. H. (2001). A argumentação em discussões sócio-científicas: reflexões a partir de um estudo de caso. Revista Brasileira de Pesquisa Em Educação Em Ciências - Porto Alegre, 1(1), 140-152.

Silva, F. L. d. (2008). A natureza me disse. Natal: Flecha do Tempo.

Tabosa, W. A. F. (2007). Uma Ecologia de base Complexa. (Doutorado), Universidade Federal do Rio Grande do Norte, Natal.

Villani, A., \& Pacca, J. L. d. A. (1997). Construtivismo, conhecimento científico e habilidade didática no ensino de ciências. Revista da Faculdade de Educação, 23.

Villani, C. E. P., \& Nascimento, S. S. d. (2003). A argumentação e o ensino de ciências: uma atividade experimental no laboratório didático de física do ensino médio. Investigações em Ensino de Ciências, 8(3), 187-209. 